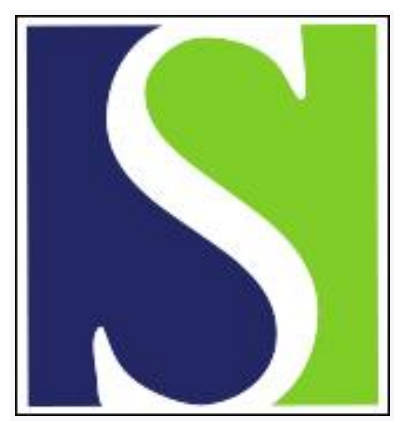

Scand J Work Environ Health 2001;27(2):85-86

https://doi.org/10.5271/sjweh.593

Issue date: Apr 2001

Shift work and cardiovascular disease - from etiologic studies to prevention through scheduling

by Härmä $M$

Affiliation: Scandinavian Journal of Work, Environment \& Health, Topeliuksenkatu 41 a A, Fl-00250 Helsinki, Finland. mikko.harma@ttl.fi

Refers to the following texts of the Journal: 1999;25(2):85-99

2001;27(2):87-96 2001;27(2):97-105

The following articles refer to this text: 2002;28(1):64-71; SJWEH

Supplements 2008;(6):169-176

This article in PubMed: www.ncbi.nlm.nih.gov/pubmed/11409600 


\section{Shift work and cardiovascular disease - from etiologic studies to prevention through scheduling}

Half of patients with coronary heart disease do not have any of the established risk factors (1). When the significance of work with respect to personal life is taken into account, it is not surprising that researchers are continually trying to identify new risk factors from the psychosocial work environment.

Shift work is one of the factors under debate. On the basis of a review of 17 studies dealing with shift work and cardiovascular disease (2), Bøggild \& Knutsson concluded, in 1999, that shift workers have a $40 \%$ increase in risk when compared with day workers. A new case-referent study controlling for job strain, age, education level, and smoking also supports the conclusion of an increased risk for shift workers (3). However, some of the published studies contained in the earlier review and a later paper (4) did not find an association between shift work and cardiovascular disease; therefore the relationship does not seem to be consistent.

In this issue of the Scandinavian Journal of Work, Environment \& Health a straightforward paper shows that, in a random sample of employees, shift workers reported high exposure to work environment factors like noise, heat, passive smoking, walking, standing, and psychosocial stress - most of which can be related to cardiovascular disease (5). The paper adds to the discussion on the methodological problems faced by studies investigating shift work and cardiovascular disease. Shiftwork populations are often self-selected $(6,7)$, and the observed weak associations allow the possibility for unaccounted confounding. Twenty-four hour operations have characteristic jobs that also vary according to the time of day. Great differences in shift workers' and day workers' work environment and stress, social class, or living habits make the interpretation of even good follow-up studies difficult.

The existing evidence for a causal relationship between shift work and cardiovascular disease seems to lack experimental evidence, dose-response studies with exact exposure information, and - perhaps most importantly - strong evidence for biological mechanisms indicating how shift work could actually increase the risk of cardiovascular disease. Since etiologic intervention studies of cardiovascular disease need large study populations and exposure contrasts (8), a clever approach has been to conduct intervention studies focusing on biomarkers for atherosclerosis or thrombosis instead of morbidity ( 9 , 10). This issue of the Scandinavian Journal of Work, Environment \& Health contains the report of an intervention study aimed at examining whether ergonomic shift scheduling changes the biomarkers of heart disease (11). The changes related to higher regularity, few consecutive night shifts, and more weekends off led to favorable changes in risk factors for ischemic heart disease. In the group with the highest number of ergonomic changes, an $8 \%$ decrease in total cholesterol, a $15 \%$ decrease in lowdensity lipoprotein (LDL) cholesterol, a $9 \%$ increase in high-density lipoprotein (HDL) cholesterol, and a $14 \%$ decrease in the total:HDL cholesterol ratio were observed. When changes in the principles of shift scheduling were analyzed across the data, higher regularity and a reduction in the number of consecutive night shifts were positively related to the biomarkers.

The study shows that the timing of work can change risk factors for cardiovascular disease. Even more important, we are informed how work schedules should be improved to reduce biomarkers for atherosclerosis, and perhaps the incidence of ischemic heart disease in the long run. However, the question concerning mechanisms remains open. The observed changes in biomarkers were not related to changes in smoking, alcohol consumption, or exercise levels at the beginning of the study. However, possible changes in diet were not measured. Meal timing has been shown to influence postprandial 
levels of lipids and glucose $(12,13)$. The present intervention resulted in only slight changes in sleep and perceived stress. The recently found effects of sleep loss on lipid metabolism, glucose tolerance, autonomous nervous activity, and cortisol patterns (14) may thus not have been the key mechanism either.

We do not know why shift work increases the risk of cardiovascular disease. There are probably many reasons, changes in circadian rhythms, life-style factors and psychosocial stress being mentioned the most frequently. Since factors like smoking, physical activity, or psychosocial stress are not "new" risk factors, only changes in circadian rhythms or factors related to sleep loss influencing the formation of atheroma or a clot of the artery wall would be really specific heart disease mechanisms for shift workers. The current study (11) shows that regularity in shifts decreased ischemic heart disease biomarkers. We still need information, however, on whether the regularity in meal patterns, sleep, physical activity, or some other circadian functions were the key factors leading to the improvement. The answers would help us to provide better recommendations for optimum schedules.

Increasing demands for flexibility in workhours is a topical issue in many firms. With respect to sleepwakefulness and job satisfaction, numerous studies indicate that regularity, predictability, a low number of consecutive night shifts, and sufficient time-off between shifts are advantageous (15). Putting cardiovascular disease and its biomarkers on the list of outcomes of future intervention studies of shift work would be welcomed.

\section{References}

1. Futterman L, Lemberg L. Fifty percent of patients with coronary artery disease do not have any of the conventional risk factors. Am J Crit Care 1998;7:240—4.

2. Bøggild H, Knutsson A. Shift work, risk factors and cardiovascular disease. Scand J Work Environ Health 1999;25(2):85-99.

3. Knutsson A, Hallquist J, Reuterwall C, Theorell T, Åkerstedt T. Shiftwork and myocardial infarction: a case-control study. Occup Environ Med 1999;56:46—50.

4. Bøggild H, Suadicani P, Hein H, Gyntelberg F. Shift work, social class, and ischaemic heart disease in middle aged and elderly men; a 22 year follow up in the Copenhagen male study. Occup Environ Med 1999;56:640—5.

5. Bøggild H, Hermann B, Tüchsen F, Jeppesen H. Work environment among Danish shift and day workers. Scand J Work Environ Health 2001;2:97-105.

6. Frese M, Semmer N. Shiftwork, stress and psychosomatic complaints: a comparison between workers in different shiftwork schedules, non-shiftworkers, and former shiftworkers. Ergonomics 1986;29(1):99—114.

7. Knutsson A, Åkerstedt T. The healthy-workers effect: self-selection among Swedish shift workers. Work Stress 1992;6(2):163-7.

8. Skov T, Kristensen T. Etiologic and prevention effectiveness intervention studies in occupational health. Am J Ind Med 1996;29:378-1.

9. Orth-Gomér K. Intervention on coronary risk factors by adapting a shift work schedule to biologic rhythmicity. Psychosom Med 1983;45:407-15.

10. Kecklund G, Åkerstedt T, Göransson B, Söderberg K. Omläggning av skiftschema: konservenser för välbefinnande, hälsa, sömn/vakenhet och arbetstrivsel: resultatrapport 2: frågeformulär, dagbok ock halsoundersökning [Changing shift schedule: effects on well-being, health, sleep/wake behaviour and work satisfaction: report of results 2: questionnaire, diary data and health examination]. Stockholm: Stressforskningsrapport no 242;1994.

11. Bøggild $\mathrm{H}$, Jeppesen $\mathrm{H}$. Intervention in shift scheduling and change in biomarkers of heart disease in hospital wards. Scand J Work Environ Health 2001;2:87-96.

12. Romon M, Le Fur C, Lebel P, Edmé J-L, Fruchart J-C, Dallongeville J. Circadian variation in postprandial lipemia. Am J Clin Nutr 19978;65:934-40.

13. Hampton S, Morgan L, Lawrence N, Anastasiodou T, Norris F, Diacon S, et al. Postprandial hormone and metabolic responses in simulated shift work. J Endocrinol 1996;151(2):259—67.

14. Spiegel K, Leprould R, Van Cauter E. Impact of sleep debt on metabolic and endocrine function. Lancet 1999;354:1435-9.

15. Knauth P. Designing better shift systems. Appl Ergon 1996;27:39—44.

Mikko Härmä, Research Professor

Editor in Chief, Scandinavian Journal of Work, Environment \& Health 